\title{
Up to date treatment of ascites in liver cirrhosis
}

\author{
Mohamed Ibrahim El Sayed*, Hany Ahmad Mohammed*
}

(*Internal medicine department-Sohag University)

\section{Introduction}

Ascites is defined as an abnormal accumulation of fluid in the abdominal cavity. Ascites is the mostcommon complication of cirrhosis, with approximately $50 \%$ of patients with compensated cirrhosisdeveloping ascites over the course of 10 years. After developing ascites that necessitateshospitalization, the risk of mortality increases to $15 \%$ at 1 year and nearly $50 \%$ at 5 years $[1,2]$. The occurrence of ascites impairs patient working and social life, often leads to hospitalization, requires chronic treatment and is a direct cause of further complications, such as spontaneous bacterial peritonitis, restrictive ventilatory dysfunction, or abdominal hernias. The development of refractory ascites carries a poor prognosis, with a 1-year survival rate of less than $50 \%$ [3]. Pathogenesis of ascites in patients with liver cirrhosis
The pathogenesis of ascites is complex and not fully understood. Portal hypertension (PHT) plays a major role in the development of ascites in patients with liver cirrhosis. The increased sinusoidal hydrostatic pressure and splanchnic capillary pressure are essential, and ascites usually develops in patients with a hepatic venous pressure gradient greater than $12 \mathrm{mmHg}$ [4].Major factors involved in the complex pathogenesis of ascites are portal and sinusoidal hypertension, arterial vasodilatation, and neurohumoral activation, all leading to sodium and water retention [5]. The triad of portal hypertension, arterial vasodilatation, and neurohumoral activation, leading to sodium and water retention, explains, to large extent, the formation of ascites [6].

Complications of ascites

-Spontaneous bacterial peritonitis

-Hepatorenal Syndrome

-Hepatic hydrothorax

-Hyponatremia 


\section{Pathophysiologic backgrounds and main theories of ascites formation in liver cirrhosis[7]}

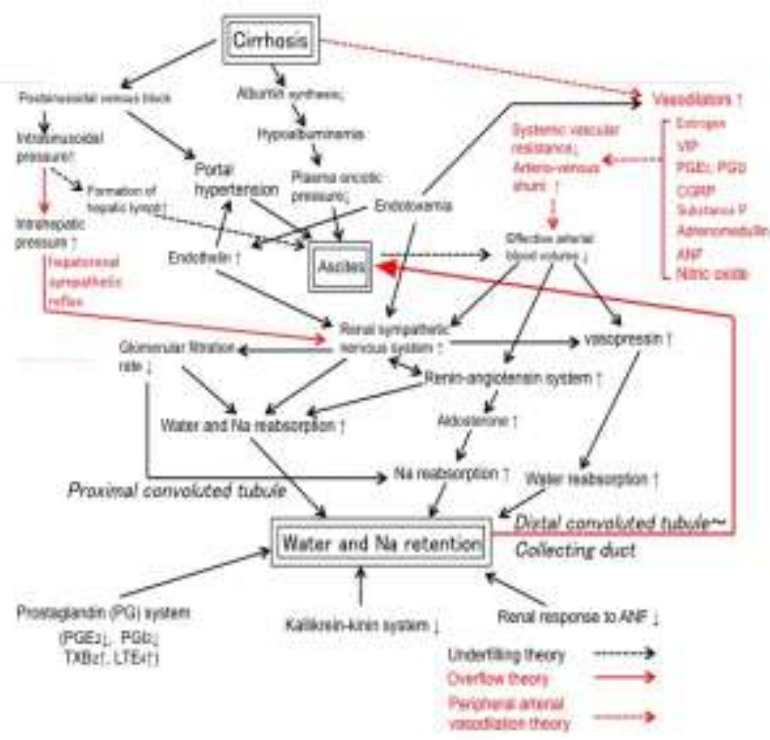

Assessment of the severity of ascites

The International Ascites Club classifies ascites according to the grade [8]Mild: Detectable only on ultrasonography, Moderate: Moderate distention of abdomen, Large: Marked distension of abdomen ("tense"), presence or absence of complications (Uncomplicated: Ascites with no infection and hepatorenal syndrome or Complicated: Ascites with infection or hepatorenal syndrome), and response to diuretic treatment (Diuretic resistant: No response to a sodium-restricted diet and high-dose diuretic treatment, Diuretic intractable: Side effects induced by diuretics preclude optimal dosing).

Definition and diagnostic criteria for refractory ascites in cirrhosis

The International Ascites Club defines refractory ascites as ascites that cannot be managed by medical therapy either because of a lack of response to maximum doses of diuretics (spironolactone $400 \mathrm{mg} / \mathrm{day}$ and furosemide $160 \mathrm{mg} /$ day) or because patients develop complications related to diuretic therapy that preclude the use of an effective dose of diuretics [9].

Diuretic-resistant ascites: ascites that cannot be mobilized or the early recurrence of which cannot be prevented because of a lack of response to sodium restriction and diuretic treatment. Diuretic-intractable ascites: ascites that cannot be mobilized or the early recurrence of which cannot be prevented because of the development of diuretic induced complications that preclude the use of an effective diuretic dosage.

Treatment of cirrhotic ascites

The approach for the treatment of ascites depends on the grade of ascites. In grade 1 or mild ascites. There are no recommendations for the treatment of grade 1 ascites[10].Patients who develop grade 2 ascites do not require hospitalisation, unless other complications are present. Grade 3 ascites can be treated with initial large volume paracentesis followed by dietary sodium restriction and diuretics (with the exception of refractory ascites) [11]. 


\section{Dietary sodium restriction and diuretics}

Dietary sodium restriction and a dual diuretic regimen with spironolactone and furosemide have been shown to be effective in more than $90 \%$ of patients in achieving a reduction in the volume of ascites to acceptable levels. Less than $10 \%$ of patients with cirrhosis and ascites are refractory to standard medical therapy $\{\mathbf{1 2}\}$.

\section{Single large volume paracentesis}

Therapeutic large volume paracentesis (LVP) should be performed to alleviate abdominal discomfort or respiratory distress in hemodynamically stable patients with tense ascites or ascites that are refractory to diuretics. There are few absolute contraindications for LVP. Coagulopathy and thrombocytopenia (both very common in cirrhotic patients) are themselves not absolute contraindications. LVP is a safe procedure, and the risk of local complications, such as hemorrhage or bowel perforation, is extremely low [13].The most effective method to preventing circulatory dysfunction after LVP is the administration of albumin.Paracentesis removes the fluid more rapidly than does careful diuresis, paracentesis does nothing to correct the underlying problem that led to the initial ascites formation, i.e., sodium retention, and it should not be viewed as first-line therapy for all patients with ascites. Dietary sodium restriction and diuretics should follow paracentesis to prevent or decrease fluid re accumulation.

\section{Serial therapeutic paracentesis}

Serial paracenteses is a safe option for patients with refractory ascites. LVP up to total paracentesis can be done on regular basis or in demand. Diuretics can be stopped in these patients, especially if urine sodium is still $<30 \mathrm{mmol} /$ day, but dietary sodium restriction should be maintained to decrease the rate of fluid accumulation. Up to $5 \mathrm{~L}$ of ascites can be taped safely without the need for albumin infusion. A concern with the administration of albumin is the added cost as well as the small infectious risk. A small study demonstrated no difference in PICD, hyponatremia, renal impairment, rate of ascites recurrence, and 6-month survival in patients receiving standard versus half albumin doses[14]; if confirmed in a larger study, this albumin infusion adjustment could help decrease costs in treating with albumin.

Transjugular intrahepatic portosystemic stent-shunt (TIPS)

TIPS reduce the portosystemic pressure gradient by shunting the blood from the portal vein to the hepatic vein and is usually inserted by an interventional radiologist using local anesthesia $[15,16]$. The main indication for TIPS is refractory ascites, uncontrolled acute variceal bleeding, and secondary prevention of gastric variceal bleed. It may have a role in hydrothorax, hepatorenal, and hepatopulmonary syndrome [17].Some studies have compared the efficacy of TIPS to LVP[18].Early studies comparing TIPS with large volume paracentesis were disappointing. Despite better control of ascites in patients undergoing TIPS, there was no survival advantage in TIPS in addition to increased morbidity due to hepatic encephalopathy and deterioration of liver function. The main complication of TIPS is the development of hepatic encephalopathy which is more reported with TIPS than with repeated large volume paracentesis[19,20].Other complications include shunt thrombosis and stenosis. Uncovered stents are 
complicated by stenosis in up to approximately $80 \%$ of cases[21].

Peritoneo-venous shunt (PVS)

PVS was designed to palliate ascites by reinfusingascitic fluid into the systemic circulationPVS prolonged the time to the recurrence of ascites compared with diuretic treatmentand LVP with albumin infusion. However, the poor long-term patency, excessive complications and no survival advantage compared with medical therapy have restricted its indication only to patients for whom other treatment modalities are impossible [22].

Cell-free and concentrated ascites reinfusion therapy (CART)

This therapy aims to maintain serum albumin levels by filtrating and concentrating the removed ascitic fluid, followed by intravenous reinfusion of the collected proteins[23]. The benefit of CART in reducing albumin use has been emphasized, although the cost of instruments for CART, higher than that of albumin solution, is considered as a drawback[7,24]. The advantages of this therapy are that albumin transfusion can be reduced; furthermore, the risk of infection or allergic reaction is reduced. However, CART is difficult to carry out in patients with SBP, because inadvertent reinfusion of filtrated, concentrated endotoxins in ascites might result in high fever or shock.

Automated Low-Flow Ascites Pump System (alfapump [AP] system)

The automated low-flow ascites pump (Alfapump) system consists of a subcutaneously implanted batterypowered programmable pump. It is connected to catheters that transfer ascites from the peritoneal cavity to the bladder, from which it is eliminated with urine. The device has internal sensors that monitor pump function. In two multicenter safety and efficacy studies, [25]Alfapumpensured a significant reduction of the number and volume of paracentesis in patients with advanced cirrhosis and refractory ascites. However, adverse effectsdirectly related to the device occurred in about onethirdto half [26] of cases. In a multicentre RCT in patients with refractory ascites, Alfapumpreduced the median number of paracentesisper month by $85 \%$ with respect to LVP, and significantly improved quality of life and nutritional parameters, as assessed by hand-grip strength and body mass index. Alfapumphad no effect on survival and was associated with a significantly higher incidence of serious adverse events (85.2 vs. 45.2\%), mainly represented by AKI [27].

Thus, even though Alfapumpis effective inreducing the need for paracentesis in patients with refractory ascites, its frequent side effects require close monitoring of patients. Indeed, in addition to device-related adverse event, itshould be noted that the evaluation of kidney and circulatory function in 10 patients with cirrhosis and refractory ascites carrying Alfapump has shown a significant GFR decline withinsix months, which was associated with a marked increase in plasma renin activity and norepinephrine concentration[28]. This likely represented the pathophysiological background of 18 episodes of AKI experienced by seven patients.

\section{Extracorporeal ultrafiltration of ascitic fluid (EUA)}

Extracorporeal ultrafiltration of ascitic fluid (EUA), which is a technique to reinject concentrated ascites continuously by using a dialyser and pump for haemodialysis, is another available means of treating refractory 
SOHAG MEDICAL JOURNAL

Vol. 23 No.2 Apr2019
Up to date treatment of ascites in liver cirrhosis

Mohamed Ibrahim and Hany Ahmad.et al ascites which was first reported by [29]. Adding an insignificant influence on the circulation [30]from EUA, intraabdominal albumin is reported to backflow to blood and it is possible to perform EUA without the complications that are sometimes encountered with intravenous reinfusion of ascites (IRA).

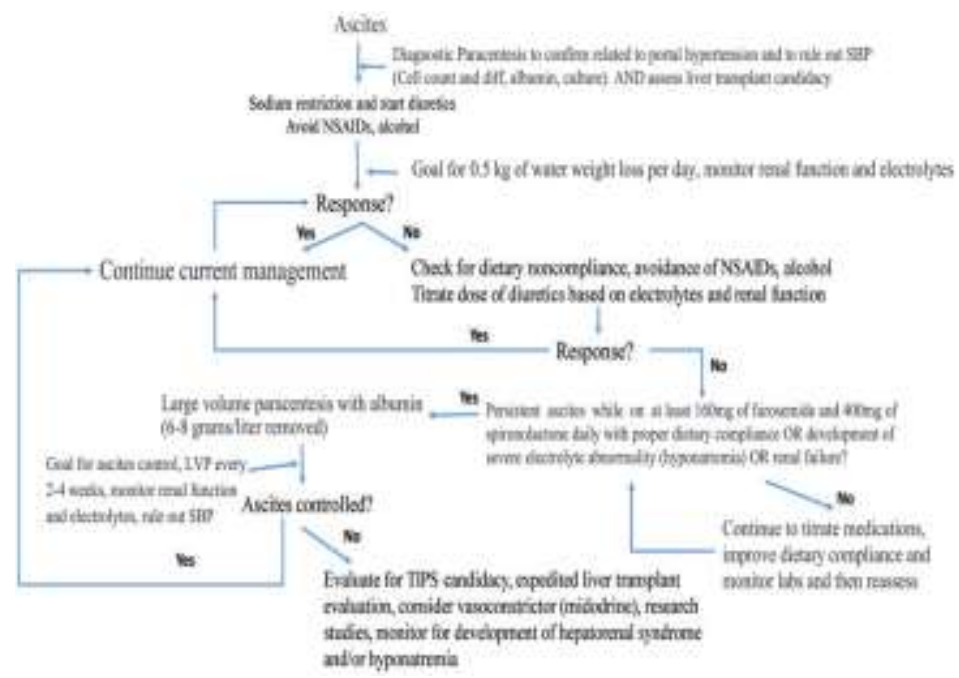

An algorithm for the management of ascites and refractory ascites[31]

\section{References}

1. Planas R, Montoliu S, Ballesté B, et al. Natural history of patients hospitalized formanagement of cirrhotic ascites. ClinGastroenterolHepatol. 2006;4:138594.

2. Runyon BA; AASLD Practice Guidelines Committee. Management of adult patients withascites due to cirrhosis: update 2012.[AASLD Practice Guidelines].

3. Fede G, D'Amico G, Arvaniti V, et al. Renal failure and cirrhosis: a systematic review of mortality and prognosis. $J$ Hepatol. 2012 Apr. 56(4):810-8.

4. Casado, M, Bosch, J and García-Pagán JC. Clinical events after transjugular intrahepatic portosystemic shunt: Correlation with hemodynamic findings. Gastroenterology. 1998;114(6):12961303.

5. Arroyo V. Pathophysiology, diagnosis and treatment of ascites in cirrhosis. Annals of Hepatology. 2002;1(2):72-79.

6. Gentilini P, Vizzutti F, Gentilini A, et al. Update on ascites and hepatorenal syndrome. Digestive and Liver Disease. 2002;34(8):592-605.

7. Fukui H. Do vasopressin V2 receptor antagonists benefit cirrhotics with refractory ascites? World J Gastroenterol. 2015; 21(41):11584 11596.

8. Moore KP, Wong F, Gines P, etal.The management of ascites in cirrhosis: Report on the consensus conference the International Ascites Club. Hepatology. 2003;38(1):258-266.

9. Sola E, Sole C and Gines P. Management of uninfected and infected ascites in cirrhosis. Liver Int. 2016;36Suppl 1:109115.

10.EASL Clinical Practice Guidelines for the management of patients with decompensated cirrhosis Journal of Hepatology 2018 vol. 69 j 406-460. 
11.Runyon BA and Aasld. Introduction to the revised American Association for the Study of Liver Diseases Practice Guideline management of adult patients with ascites due to cirrhosis 2012. Hepatology 2013; 57: 1651-1653.

12.Santos J, Planas R, Pardo A, et al. Spironolactone alone or in combination with furosemide in the treatment of moderate ascites in nonazotemic cirrhosis. A randomized comparative study of efficacy and safety. Journal of Hepatology. 2003;39(2):187-192.

13.Pache $I$ and Bilodeau M. Severe haemorrhage following abdominal paracentesis for ascites in patients with liver disease. Alimentary Pharmacology \& Therapeutics. 2005;21(5):525-529.

14.Alessandria C, Elia C, Mezzabotta L, et al. Prevention of paracentesis-induced circulatory dysfunction in cirrhosis: standard vs half albumin doses. A prospective, randomized, unblinded pilot study. Dig Liver Dis. 2011;43(11):881886.

15.Rossle M, Ochs A, Gulberg V, et al. A comparison of paracentesis and transjugular intrahepatic portosystemicbshunting in patients with ascites. New England Journal of Medicine. 2000;342(23):1701-1707

16. Deltenre $P$, Mathurin $P$, Dharancy $S$ et al. Transjugular intrahepatic portosystemic shunt in refractory ascites: a metaanalysis. Liver Int 2005; 25: 349-356.

17.Rossle M. TIPS: 25 years later. Journal of Hepatology. 2013;59(5):1081-1093.

18. La Mura V and Salerno F. Therapy of the refractory ascites: Total paracentesis vs. TIPS. Gastroenterología y Hepatología2015;39(7):477-480.

19.Saab S, Nieto JM, Lewis SK, et al. TIPS versus paracentesis for cirrhotic patients with refractory ascites. The Cochrane Database of Systematic Reviews. 2006;(4):CD004889 .

20.Salerno $\mathrm{F}$, Cammà $\mathrm{C}$, Enea $\mathrm{M}$, et al. Transjugular intrahepatic portosystemic shunt for refractory ascites: A meta-analysis of individual patient data. Gastroenterology. 2007;133(3):825-834.
21.Boyer TD and Haskal ZJ, D. American Association for the Study of Liver. The role of transjugular intrahepatic portosystemic shunt in the management of portal hypertension. Hepatology. 2005;41(2):386-400.

22. Fukui H, Saito $H$, Ueno $Y$, et al. Evidence-based clinical practice guidelines for liver cirrhosis 2015. J Gastroenterol 2016; 7: 629-650.

23. Inoue $\mathrm{N}$, Yamazaki $\mathrm{Z}$, Oda $\mathrm{T}$, et al. Treatment of intractable ascites by continuous reinfusion of the sterilized, cell-free and concentrated ascitic fluid. Transactions - American Society for Artificial Internal Organs 1977; 23: 699702.

24.Zaak D, Paquet KJ and Kuhn R. Prospective study comparing human albumin vs. reinfusion of ultrafiltrateascitic fluid after total paracentesis in cirrhotic patients with tense ascites. $\mathrm{Z}$ Gastroenterol. 2001;39(1):5-10.

25. Bellot P, Welker MW, Soriano G, et al. Automated low flow pump system for the treatment of refractory ascites: a multicenter safety and efficacy study. J Hepatol 2013;58:922-927.

26.Stirnimann G, Berg T, Spahr L, et al. Treatment of refractory ascites with an automated low-flow ascites pump in patients with cirrhosis. Aliment PharmacolTher 2017;46:981-991.

27. Bureau C, Adebayo D, Chalret de Rieu $\mathrm{M}$, et al. Alfapump_ system vs. large volume paracentesis for refractory ascites: A multicenter randomized controlled study. J Hepatol 2017;67:940949.

28. Sola E, Sanchez-Cabus S, Rodriguez E, et al. Effects of alfapump system on kidney and circulatory function in patients with cirrhosis and refractory ascites. Liver Transpl 2017;23:583-593.

29.Hariprasad MK, Paul PK, Eisinger RB, et al. Extracorporeal dialysis of ascites. A new technique. Arch Intern Med 1981; 141: 1550-1551.

30.Raju SF and Achord JL. The efects of dialytic ultrafiltration and peritoneal reinfusion in the management of diuretic 
SOHAG MEDICAL JOURNAL Up to date treatment of ascites in liver cirrhosis

Vol. 23 No.2 Apr2019

Mohamed Ibrahim and Hany Ahmad.et al

resistantascites. Am J Gastroenterol 1984; 79: 308-312.

31. Brett Fortune and Andres Cardenas. Ascites, refractory ascites and

hyponatremia

in

Gastroenterology Report 2017;5(2): 104-

112 